\title{
Jogo patológico: uma abordagem terapêutica combinada
}

\author{
Pathological gambling: a combined therapeutic strategy
}

\author{
Maria Engel de Oliveira e Ana Cristina Sáad
}

\begin{abstract}
Resumo
Jogo patológico é um transtorno psiquiátrico inserido nos manuais diagnósticos há pouco mais de 20 anos, sendo até hoje pouco estudado. Pode ser considerado um transtorno do espectro impulsivo-compulsivo, apresentando características compartilhadas com os transtornos por uso de substâncias psicoativas. São identificadas três fases no comportamento de jogar: fase da vitória, da perda e do desespero. Neste artigo será apresentado o caso clínico de uma paciente com o diagnóstico de jogo patológico. Pretendemos com este caso discutir os aspectos relacionados com a abordagem combinada do caso (medicamentosa e psicológica) e as teorias atuais a respeito do jogo patológico.
\end{abstract}

Palavras-chave: jogo patológico, tratamento, co-morbidade.

\begin{abstract}
Pathological gambling has been considered a psychiatric disorder for no longer than 20 years, still being not well studied. It can be considered an impulsive-compulsive spectrum disorder with shared characteristics with substance use disorder. There are three phases that can be identified in the gambling behavior: victory, loss and despair. This article will show a case report of a patient diagnosed as pathological gambler. We intend to discuss some aspects related to the combined approach (medication plus psychotherapy) and present theories about pathological gambling. Key words: pathological gambling, treatment, comorbidity.
\end{abstract}

Instituto de Psiquiatria da Universidade Federal do Rio de Janeiro (IPUB/UFRJ) (Oliveira ME, Sáad AC) Pontifícia Universidade Católica do Rio de Janeiro (PUC-RIO) (Oliveira ME)

Recebido

10-01-06

Aprovado

15-03-06

Correspondência para: Maria Engel de Oliveira

Largo dos Leões, 81/1005 - Humaitá - 22260-210 - Rio de Janeiro-RJ - Tel.: (021) 2286-1724 - e-mail: mariaengel@ gmail.com 


\section{Introdução}

O jogo patológico é um transtorno psiquiátrico reconhecido com esse status há pouco mais de 20 anos. Atualmente está inserido na décima revisão da Classificação Estatística Internacional de Doenças e Problemas Relacionados à Saúde (CID-10), capítulo V: Classificação de Transtornos Mentais e Comportamentais (1993), como F63.0 (Transtornos dos Hábitos e dos Impulsos). No Manual de Diagnóstico e Estatística das Perturbações Mentais IV (DSM-IV), 1994, está localizado no capítulo 14, como um dos "transtornos de controle de impulsos não classificados em outro local".

O jogador social é aquele que pára de jogar a qualquer hora, independentemente de estar ganhando ou perdendo. Sua auto-estima não está ligada a ganhar ou perder, pois outros aspectos da vida são mais importantes e recompensadores do que o jogo, no qual raramente irá ter alguma experiência de grande ganho (Custer, 1984). Para jogadores patológicos, o jogo tem um poder de gerar tensão importante, principalmente na perda, e essa tensão aumenta o impulso de jogar. Eles geralmente têm inteligência superior, são muito competitivos e trabalhadores, além de possuírem alto grau de energia, habilidades atléticas e boas notas na escola. Normalmente têm sucessos em desafios, são atraídos por situações muito estimulantes e não suportam monotonia ou tarefas repetitivas. 0 jogo, dependendo do resultado, altera sua auto-estima, pois, se ganham, sentem-se poderosos e importantes e, se perdem, fracassados (Custer apud Oliveira et al., 1996).

Os poucos dados disponíveis sobre a prevalência do jogo patológico sugerem uma incidência em torno de 1\% a 3\% na população adulta (DSM-IV, 1994). No Brasil, em 1998, o bingo já era o jogo preferido de $65 \%$ dos jogadores compulsivos e, em 2001, essa preferência subiu para 90\% (Ballone, 2003). Apesar de existirem milhares de casos de pessoas com esse transtorno, há escassos estudos publicados e com pouco conhecimento quanto à prevalência e o impacto do jogo patológico no Brasil.

Recente pesquisa constatou que entre 171 freqüentadores de casas de apostas, 75 foram diagnosticados como jogadores patológicos. Desses, a maioria era composta de homens $(87,7 \%)$ - a metade deles casada $(50,7 \%)$ - e tinha formação educacional de ensino médio ou superior $(82,3 \%)$, empregos em regime integral $(71,6 \%)$, média de idade em torno dos 40 anos e uma renda mensal média de $\mathrm{R} \$ 4$ mil (Oliveira apud Tavares et al., 1999).

Nos últimos anos o que se observa é um aumento de mulheres com problemas relacionados ao jogo, assim como vem ocorrendo em relação à dependência de álcool e outras drogas. Aproximadamente um terço dos indivíduos com o transtorno jogo patológico é composto de mulheres que apresentam maior propensão à depressão e à jogatina como fuga (Tavares et al., 2004).

O jogo patológico também tem sido considerado um distúrbio do espectro impulsivo-compulsivo sem drogas, pois as sensações experimentadas por jogadores são descritas como similares às experimentadas por usuários e dependentes de drogas. É comum a co-morbidade com patologias de caráter não-impulsivo, como os transtornos do humor e de ansiedade. Características específicas (fissura, exclusão de outras áreas da vida, tolerância e síndrome de abstinência) são apontadas como indícios marcantes e presentes no jogador patológico para o qual 0 ato de jogar seria uma forma de aplacar sensações de ansiedade e de depressão (Custer, 1984). Porém, apesar de classificado entre os "transtornos do controle do impulso", o jogo patológico apresenta uma natureza compulsiva devido ao ato de jogar para evitar estados emocionais desfavoráveis, o que está associado à sintomatologia ansiosa (Tavares, 2000).

Quanto ao tratamento do jogo patológico, existem várias modalidades de intervenção que, se aplicadas em conjunto, poderão ser mais eficazes (O'Brien et al., 1999).

Algumas dessas intervenções são listadas a seguir: - psicoterapia individual, cujo principal objetivo apontado é incentivar o jogador a compreender as razões pelas quais é levado a jogar e a lidar com os seus sentimentos de impotência, depressão e culpa;

- grupos de auto-ajuda como Jogadores Anônimos (JA), que seguem a mesma proposta dos outros grupos voltados para 0 acompanhamento de pessoas com problemas relacionados ao uso indevido ou abusivo de álcool e outras drogas: Alcoólicos Anônimos (AA), Narcóticos Anônimos (NA), Nar-Anon, etc.; - terapia familiar, pois as mentiras, os enganos, a falta de confiança e os problemas financeiros criados pelos comportamentos dos jogadores patológicos podem criar problemas também para os familiares. Abre-se então, com a terapia familiar, um espaço de fala e reflexão para os familiares do paciente;

- tratamento farmacológico, em relação a esse auxílio terapêutico, há resultados positivos com o uso de estabilizadores de humor e antidepressivos, pois a melhora dos pacientes está muito associada ao alívio dos sintomas de depressão e ansiedade que são co-morbidades à patologia.

O objetivo deste trabalho consiste em relatar o caso clínico de uma paciente com diagnóstico de jogo patológico acompanhada com uma intervenção combinada (psicoterapia psicanalítica e farmacoterapia).

\section{Relato de caso}

Paciente W., 37 anos, sexo feminino, parda, solteira, terceiro grau com formação em Direito. Foi atendida no Ambulatório do Instituto de Psiquiatria da Universidade Federal do Rio de Janeiro (IPUB/UFRJ), na Recepção do Programa de Estudos e Assistência ao Uso Indevido de Drogas (PROJAD) no ano de 2003.

Na primeira entrevista com a psicóloga de plantão, a paciente estava muito nervosa, chorosa, sentindo-se perdida, "no fundo do poço", e sem saber mais o que fazer. Devido ao jogo contraiu diversas dívidas, relatou estar devendo em torno de $\mathrm{R} \$ 17$ mil. Referiu freqüentar bingos com certa constância ( \pm cinco vezes em quatro dias na semana), e que começou a jogar há cerca de cinco anos. Também se sentia muito envergonhada, sem conseguir voltar para casa, o que a levou a perambular pelas ruas e a pedir esmolas depois de ter perdido todo o dinheiro que ganhou em um bingo. Apresentava-se com aparência muito descuidada, cabelos maltratados, roupas em desalinho e fisicamente cansada. Dizia "ganhar dinheiro não é problema, o problema é ficar com ele na mão, é uma compulsão, não consigo me controlar" (sic). 
Atuava profissionalmente como advogada, mas gastava tudo que ganhava jogando em bingos.

A terapeuta sugeriu no início do tratamento que se mantivessem em contato por três sessões semanais, pois era preciso ocupar o tempo ocioso da paciente a fim de evitar idas mais constantes dela aos bingos. Porém ela não comparecia a todas as sessões, se justificando muitas vezes por não estar conseguindo chegar a tempo. Atrasos também eram constantes, algumas vezes decorrentes de suas idas a bingos.

0 tratamento medicamentoso adotado foi fluoxetina $10 \mathrm{mg} / \mathrm{dia}$, com aumento gradual da dose até chegar a $60 \mathrm{mg} /$ dia, pois a paciente também apresentava quadro de depressão como co-morbidade.

W. percebeu, com o decorrer de seu tratamento, que era capaz de ficar com determinada quantia que ganhava no bingo sem precisar apostar tudo novamente, ficando então muito feliz com esse importante passo para sua melhora. A paciente ficou em tratamento no ambulatório do IPUB/UFRJ por praticamente um ano, perfazendo um total de 38 sessões.

Ao final do tratamento, referiu sentir menos fissura por jogo do que antes, conseguindo guardar dinheiro e atuar em sua área de trabalho, e continuou freqüentando bingos, mas no máximo duas vezes por semana.

A medicação foi mantida durante todo o seu tratamento ambulatorial, aproximadamente um ano. Ao fim de 2004, a paciente interrompeu o tratamento, referindo estar muito ocupada em razão de estudos voltados para concursos na sua área de trabalho.

\section{Discussão}

A abordagem teórica utilizada para a compreensão do caso foi a teoria psicanalítica. Segundo Figueiredo (2002), para que se efetue um trabalho clínico baseado na psicanálise e que seja diferente do campo das psicoterapias em geral, existem três condições mínimas.

A primeira condição é que haja o contato com a realidade psíquica, cuja fonte primária é o inconsciente do sujeito. É na própria palavra do sujeito que começa o trabalho clínico, pois o tratamento do sofrimento psíquico só pode ser feito pelo que aparece dessa realidade em palavras e ações prenhes de sentido. A segunda condição é a transferência que se efetua dentro do trabalho clínico, na relação que se estabelece entre terapeuta e paciente. De início o paciente transmite sua queixa para o outro, aquele que o atende e que pode curá-lo. Depois, com o decorrer dos atendimentos, a sua queixa é transformada em questão, a transferência então deixa de ser uma expectativa imediata de cura para se transformar em transferência analítica. A terceira condição é o trabalho da interpretação, que é um recurso do terapeuta. Deve-se ter em mente que uma palavra e/ou ação do terapeuta só tem valor de interpretação, como efeito, num tempo posterior, pois o tempo para a psicanálise não é linear ou evolutivo. Trabalha-se com uma retroação do tempo atual sobre 0 anterior, seja no trauma, seja na construção da fantasia, no sintoma ou na cena analítica (Figueiredo, 2002).

No caso clínico apresentado neste trabalho houve um interesse inicial por parte da terapeuta em investigar a história pessoal e familiar da paciente. O problema de W. com o jogo patológico foi compreendido, tendo como base os conflitos familiares vividos de forma muito sofrida e traumática. Com o decorrer do tratamento a terapeuta pôde entender, ao lado da paciente, que suas idas a bingos eram fomentadas por uma espécie de fuga dos problemas no seu meio familiar. $W$. se referia à mãe como ausente em muitos momentos de sua vida e, ao mesmo tempo, muito controladora e invasiva. 0 pai se suicidou quando ela tinha 12 anos, fato que a fez sentir-se culpada.

Entre os temas discutidos no decorrer do seu tratamento, destaca-se sua impossibilidade de entrar em contato emocional direto com tantas faltas. É como se, de forma inconsciente, ela buscasse no jogo alguma sensação que aplacasse e/ou que preenchesse essa falta do pai e 0 desamparo da mãe.

As três fases do comportamento de jogar estudadas por Custer (1984) são as fases da vitória, da perda e do desespero. Na primeira, as vitórias tornam-se cada vez mais excitantes e 0 indivíduo passa a jogar com maior freqüência, acreditando que é um apostador excepcional. Na segunda, a atitude de otimismo não-realista passa a ser característica do jogador patológico. A perda passa a ser difícil de ser tolerada. 0 dinheiro que ganhou no jogo é utilizado para jogar mais e, em seguida, o indivíduo emprega o salário, as economias e o dinheiro investidos. Já na fase do desespero há um aumento de tempo e dinheiro gastos com o jogo e o afastamento da família. Exaustões física e psicológica são comuns, pois o indivíduo tenta de todas as formas saldar suas dívidas contraídas em jogo.

Quando W. chegou ao ambulatório já estava na fase do desespero, pois as dívidas que havia contraído eram exorbitantes. Ela não sabia mais o que fazer para saldá-las, mas tinha consciência de que não conseguiria parar de jogar sem ajuda profissional. As suas relações com a família já estavam se deteriorando, e seu cuidado com a aparência estava completamente abandonado. Nas sessões também não parava de chorar quando começava a falar a respeito de sua condição psicológica na época. Sentia-se extremamente desamparada e sozinha, não tendo mais a quem recorrer. A fase da vitória tinha passado há algum tempo. Já não estava sentindo prazer em ir a bingos como antes, não jogava mais por diversão e sim por impulso.

Quanto à fase da perda, pode-se dizer que antecedeu a do desespero, mas também se observou que a paciente deslizava pelas duas fases no decorrer do tratamento, pois enquanto não interrompeu suas idas aos bingos igualmente não cessaram suas apostas altas de dinheiro nas rodadas, seus gastos com várias cartelas de uma só vez e, conseqüentemente, suas perdas irreparáveis. W. via no bingo uma solução para pagar suas contas, suas dívidas e colocava seu trabalho em segundo plano.

É importante ressaltar que ao fim do tratamento houve a possibilidade de controle do ato de jogar por parte da paciente. No início freqüentava bingos com uma assiduidade de cinco vezes em quatro dias por semana, sem controle algum de quanto havia gastado por dia. Ao final, passou a freqüentar bingos duas vezes por semana, sabendo que não gastaria mais do que duzentos reais. Tal valor foi estipulado pela própria paciente, que passou a ter uma percepção mais 
realista sobre seus gastos no jogo. De início, ela se preocupou em como faria para deixar de ir ao bingo, depois substituiu tal preocupação por um controle do seu ato de jogar, fato extremamente terapêutico e eficaz para a sua melhora.

\section{Conclusão}

A paciente referida neste trabalho preencheu os critérios diagnósticos para jogo patológico e transtorno depressivo, e obteve sucesso com o tratamento. Além da intervenção medicamentosa, a abordagem psicológica considerada referencial no atendimento dessa paciente foi a psicanalítica. Essa compreensão, entretanto, não foi a única privilegiada durante o tratamento, pois técnicas de controle do impulso

\section{Referências}

American Psychiatric Association. Manual Diagnóstico e Estatístico dos Transtornos Mentais (DSM-IV). 4 ed. Porto Alegre: Artes Médicas; 1994.

Ballone GJ. Jogo compulsivo ou patológico. PsiqWeb, 2003. Disponível em: <http://gballone.sites.uol.com.br/temas/jogo.html>. Acesso em: 5 jul. 2004.

Custer RL. Profile of the pathological gambler. J Clin Psychiatry, 45(12 Pt 2): 35-8, 1984.

DeCaria CM, Hollander E, Grossman R et al. Diagnosis, neurobiology, and treatment of pathological gambling. J Clin Psychiatry, 57: 80-4, 1996.

Figueiredo AC. Vastas confusões e atendimentos imperfeitos: a clínica psicanalítica no ambulatório público. 3 ed. Rio de Janeiro: RelumeDumará, 2002.

O'Brien P et al. Psychiatric nursing: an integration of theory and practice. New York: McGraw-Hill; 1999 de jogar (comportamentais) também foram utilizadas. Porém, "a resposta ao tratamento parece depender menos da orientação teórica que o terapeuta segue e mais de um programa de consultas concatenadas, em uma ordem que faça sentido para o paciente, numa freqüência de pelo menos uma vez por semana" (DeCaria et al., 1996 apud Tavares et al, 1999).

Outra questão importante para reflexão diz respeito ao desenvolvimento de novas estratégias de tratamento para os jogadores patológicos, visto que nesse caso a paciente foi atendida em um ambulatório que oferece atendimento ao uso indevido de drogas. Acreditamos que um trabalho de equipe, com profissionais mais especializados nesse tipo de transtorno, fosse capaz de oferecer um tratamento mais eficaz num menor espaço de tempo.

Oliveira MP, Borges MB, Ribeiro $C$ et al. Jogo patológico. In: Xavier $\mathrm{D}$, Gorgulho M. Dependência, compreensão e assistência às toxicomanias: uma experiência do PROAD. São Paulo: Casa do Psicólogo, 1996.

Tavares H. Jogo patológico e suas correlações com o espectro impulsivocompulsivo. Tese de Doutorado. São Paulo: Faculdade de Medicina da Universidade de São Paulo, 2000.

Tavares H, Gentil V, Oliveira C et al. Jogadores patológicos, uma revisão: psicopatologia, quadro clínico e tratamento. Rev Psiquiatr Clin 26(4): 1-14, 1999

Tavares H, Martins S, Lobo D et al. Jogo patológico em mulheres: uma revisão, 15/06/2002. Disponivel em: <http://www.sppc.med.br/mesas/ silviasaboia.html>. Acesso em: maio 2004

World Health Organization. Classificação de transtornos mentais e de comportamento da CID-10. Porto Alegre: Artes Médicas, 1993. 